\title{
Responding to crises and disasters: the role of risk attitudes and risk perceptions
}

Joost M.E. Pennings ALEX Marketing-Finance Chair, Department of Marketing, Department of Finance, Maastricht University, The Netherlands ${ }^{1}$ and Daniel B. Grossman Candidate for MD/MBA, Medical Scholars Program, University of Illinois College of Medicine at Urbana-Champaign, United States

Discussions are taking place both in the United States and in Europe about how governments should respond to both disasters and crises, and how citizens' non-desirable behaviour might be managed with respect to such disasters. Here we examine the role that risk attitudes and risk perceptions play in decision making behaviour of individuals in times of crises and disasters and how knowledge about individual behaviour and its drivers may be helpful when developing policy. The proposed framework complements the existing literature, thereby further enriching the knowledge of crises and disaster management.

Keywords: communication, consumer behaviour, disaster, policy, risk analysis, uncertainty

\section{Introduction}

The Government warned tonight that new terrorist attacks were planned against the United States in the next week, but it offered no specifics about the nature of the attacks or what the targets might be (Rosenbaum and Johnston, 200I).

For decades, experts had warned of a bioterrorist attack . . Federal officials, faced with a chaotic situation that changed hourly, were first faulted for being alarmist as they shut down the House of Representatives, and then for under-reacting tragically by minimizing the threat (Chen et al., 200I).

'The conditions have to be absolutely perfect to have a hurricane become this strong,' said then-National Hurricane Center Director Max Mayfield, noting that Katrina may yet be more powerful than the last Category 5 storm, 1992's Hurricane Andrew, which at 165 mph leveled parts of South Florida, killed 43 people and caused \$31 billion in damage. 'It's capable of causing catastrophic damage,' Mayfield said. 'Even well-built structures will have tremendous damage. Of course, what we're really worried about is the loss of lives' (Breed, 2005).

Jefferson Parish President Aaron Broussard said some who have ridden out previous storms in the New Orleans area may not be so lucky this time. 'I'm expecting that some people who are die-hards will die hard,' he said (Breed, 2005).

The world is increasingly exposed to potential disasters and crises and, as a result, the role of both government and corporate policy makers becomes progressively more 
complicated. The inability to respond swiftly and effectively to a crisis can devastate an entire community, a company, and even an industry across a country or continent. Crises with an uncertain content (for example, a deadly outcome for citizens) and uncertain likelihood of actually being exposed to that content are particularly hard to manage for policy makers. Examples of crises exhibiting great uncertainty with profound impacts on a group of citizens include terrorism, natural disaster, disease epidemic, food contamination, and product defectiveness.

Terrorist attacks, such as that on II September 200I, and natural disasters, such as Hurricane Katrina in 2005 , clearly showed that policy makers and government officials must understand how and why their citizens react in the face of such disasters. The looming - and highly uncertain — prospect of a world-wide avian influenza, for example, creates a condition where citizen behaviour may contribute to potential loss of human life and to the demise of international poultry industries. Corporations must respond to consumer crises related to defective products as well, as exhibited by the Johnson and Johnson Tylenol tampering in 1982 and US Firestone tyre cases in 2002. Furthermore, the mad cow disease crisis in Germany showed that the cumulative effect of citizen decisions (in this case the consumption of beef) may bring an entire industry to the edge of bankruptcy (Pennings et al., 2002).

The characterization of the risks involved with these events is not in question. Rather, the effective delivery of communication about the risks will largely define how successfully those risks are characterized (National Research Council, I996). The above examples of crises and disasters provide evidence for an organized approach to risk communication from a policy standpoint, building upon the accepted practice of adequately informing involved parties from a respected and trusted source (National Research Council, I989). Furthermore, the examples above show that there is a need for a framework that allows for a better understanding of decision making behaviour in times of crisis and disaster. Such a framework can complement the existing concepts on disaster management (see Barton, I969; Tierney, I993; Quarantelli, I997; Tierney et al., 200I) and may help to formulate an effective policy tool to manage crises and disasters. In particular such a framework would be able to address two of the essential components in the management of disasters: allowing 'the adequate processing of information' and permitting 'the proper exercise of decision-making' (Quarantelli, I997, p. 45) through effective management of elements of the social, psycho-social, and cognitive decision making processes used by community members in the face of a crisis (Tierney et al., 200I).

The objective of this paper is to increase our understanding of the role of risk attitudes and risk perceptions in individual decision making behaviour in times of crises and disasters and how such a risk behaviour framework may be used as a tool to manage uncertain crises and to formulate effective strategies to respond to citizens' reactions. Established bodies of work exist with respect to both disaster communication (for example, Mileti et al., I990; Quarantelli, I990; Mileti and Fitzpatrick, I992) and to decision making by individuals and groups in crisis situations (for example, Fritz and Marks, I954; Fritz, I96r; Barton, I969; Drabek and Haas, I969; Dynes, 
I970; Sims and Baumann, I972). This paper examines the drivers of individual decision making behaviour in times of disasters, thereby extending the established works by creating a bridge between disaster communication and decision making by individuals and groups.

The remainder of this paper is organized as follows. First, building on the risk behaviour literature, we introduce a conceptual model that explains citizen behaviour in times of risk and uncertainty. The main drivers in this model are risk attitudes and risk perceptions. Second, since policy makers are not only confronted with the individual risk behaviour of citizens, but also have to deal with the behaviour of all citizens, we focus as well on the behavioural outcome space (BOS) which represents cumulative effect of all individual behaviours. Based on the conceptual model, we show how policy makers can influence the BOS in order to manage crises. We discuss the conceptual model in the context of September II, and the subsequent use of the Homeland Security Advisory System (HSAS), and Hurricane Katrina's 2005 US landfall. Finally, we conclude with a discussion.

\section{Conceptual framework}

The risk behaviour literature (Pratt, I964; Arrow, I97I; MacCrimmon and Wehrung, I986; Slovic, I987; Pennings and Wansink, 2004) identifies two dimensions that play an important role in how decision makers respond to risk: the content of the risk and the likelihood of actual exposure to that content. The first dimension refers to the impact of an event: the possibility of a young child contracting chickenpox or the common cold in the general population carries different consequences (i.e., contents) than a possible nuclear attack by terrorists. For most decision makers, the latter situation would have a greater impact than the former, as the consequences of a nuclear attack seem to reach much further than a child contracting chickenpox or a normally-healthy adult catching a cold. The second dimension reflects the likelihood of the risk content actually becoming manifest. This likelihood can either be known or unknown, whereby the former situation is referred to as risk, the latter as uncertainty (Knight, I933). Hirshleifer and Riley (I992) disregard Knight's distinction between risk and uncertainty, but make a distinction between hard and soft probability. Other researchers use the term ambiguity when referring to the situation when probabilities of the event are not known.

These two dimensions, risk content and the likelihood of exposure, are directly related to the two fundamental drivers of decision-making behaviour under risk and uncertainty: risk attitude and risk perception (Pratt, I964; Arrow, I97I; Pennings and Wansink, 2004). Risk attitude reflects a decision maker's general predisposition to a particular risk in a consistent way, and hence is formed by the content of that risk (i.e., the first dimension). Risk perception reflects the decision maker's own interpretation of the likelihood of being exposed to the content of the risk, and may therefore be defined as a decision maker's assessment of the uncertainty of the risk content inherent in a particular situation (Pennings and Smidts, 2000; Pennings and Smidts, 
2003). Hence, it is driven by the likelihood of exposure to the risk content (i.e., the second dimension). Risk attitudes range from extremely risk averse (i.e., refusing any risk under any condition) to extremely risk seeking (i.e., always preferring a riskcarrying outcome), while risk perceptions range from high to no risk perception at all (i.e., perceiving a high likelihood of the risk content occurring versus perceiving the likelihood to be minimal).

The framework that we propose is based on the notable research done by Pratt (I964) and Arrow (I97I). In Pratt and Arrow's work, risk management, reflected in the risk premium $\pi$, is a function of risk attitude (risk aversion $r$ ), the situation (base wealth $W$ ) and perceived risk (with a mean of $\bar{\varepsilon}$ and variance $\sigma^{2}$ of source of additional wealth $\sigma^{2}$ ). Pratt's risk premium $(\pi)$, which would leave the decision maker indifferent between being exposed to the risk or not being exposed to the risk, can be formulated as: $E U(W+\varepsilon)=U(W+\bar{\varepsilon}-\pi)$, where $E U$ is the expected utility. In the expected utility model this translates into:

$$
E U(W+\varepsilon)=\int U(W+\varepsilon) f(\varepsilon) d \varepsilon=U\left(W+\int \varepsilon f(\varepsilon) d \varepsilon-\pi\right)
$$

where $U($.$) is the von Neumann-Morgenstern utility and f($.$) the probability density$ function of additional wealth $\varepsilon$. It can be shown that the risk premium $\pi$ is equal to

$$
\pi=\frac{1}{2} \int \varepsilon^{2} f(\varepsilon) d \varepsilon \frac{-U^{\prime \prime}(W)}{U^{\prime}(W)} \text {, which can be written as: } \pi=\frac{1}{2} \sigma^{2} r(W),
$$

where $r(W)=-U^{\prime \prime}(W) / U^{\prime}(W)$, the Pratt-Arrow coefficient of absolute risk aversion. Equation I demonstrates that risk management behaviour depends on risk attitude $r(W)$, risk perception $\sigma^{2}$, and their interaction (Pratt, I964; Arrow, I97I; Pennings and Wansink, 2004).

Based on the risk behaviour theory, the behaviour of a decision maker in times of a crisis or disaster can be formulated as:

$$
B_{i}=f\left(R A_{i}+R P_{i}+R A_{i}^{*} R P_{i}\right)
$$

where $B_{i}$ is the risk behaviour of decision maker $i, R A_{i}$ the decision maker's $i$ risk attitude, $R P_{i}$ decision maker's $i$ risk perception and $R A_{i} * R P_{i}$ and the interaction between the two.

Pennings and Wansink (2004) showed that by de-coupling risk response behaviour into the separate components of risk perception and risk attitude (as is done in Equations [I] and [2]), a more robust conceptualization and prediction of consumer reactions is possible. The insights that result from de-coupling risk perceptions and risk attitudes can yield important managerial implications.

If risk perception is the main driver of citizens' reactions, effective communication of research information will be a powerful tool in changing behaviour. Providing and communicating the 'true' probabilities of being exposed to the risk (when possible) will 
then be a useful way to respond to citizens' concerns. If, on the other hand, risk attitude is the true driver behind citizens' responses, effective communication of the probabilities of risk exposure will have little influence on citizen behaviour, even if these probabilities are small. Instead, policy makers will have to focus on the content of the risk.

Different sources of risk information (for example, Kasperson et al., I988; Viscusi, I997; Menon et al., 2002) and different operationalizations and presentations of the risk probabilities (for example, Tversky and Kahneman, I98I; National Research Council, I989; Heath et al., I995) are known to alter the public perception of the risk, and consequently public behaviour. The presentation of risk probabilities are often difficult for citizens to understand. Comparisons to previously known singular dimension risks are often used by policy makers (National Research Council, I989). These comparisons do not necessarily consider that different events carry different characteristics. Because risk attitudes and risk perceptions are context specific, comparisons between consequences are difficult. The comparisons must not trivialize the potential crisis, yet also must be meaningful enough to be effective (National Research Council, I989). Different operationalizations can be used to compare risks, including probabilities (quantitative or percentage) and I-in-X outcomes (such as death or injury). However these operationalizations may lead to different responses, a phenomenon known as the framing effect (Tversky and Kahneman, I98I).

\section{Behavioural outcome space}

In times of crises, policy makers are not dealing with the risk behaviour of a single decision maker. Rather, they are responding to the behaviours of a large number of decision makers. Often, the behaviours of citizens in times of crises are heterogeneous: some citizens will not be affected by the ongoing threats at all, while others may react by buying extra food, evacuating, hoarding antibiotics, barricading their homes, and so on. The behavioural outcome space (BOS) reflects the variety of citizens' reactions to a (potential) crisis. The BOS is defined as the set of all individual behavioural outcomes and as such is the aggregate behaviour that policy makers are confronted with (for example, Pennings et al., 2005). Following equations (I) and (2), the BOS, which contains all possible behaviours of decision makers, is spanned by the decision makers' risk attitudes and risk perceptions. Furthermore, we hold that the BOS is driven by the interaction between decision makers as well: the fact that the neighbours are buying equipment to protect themselves against terrorist threats or are evacuating to avoid a storm may influence our own behaviour. Therefore, the behavioural outcome space is the summation across all behaviours of a community or cohort, as well as the interaction between them. It can be written as:

$$
\begin{aligned}
& \text { BOS }=\int_{i=1}^{I} B_{i}+B_{i+1} \ldots . . B_{I}+B_{i} * B_{i+1} \ldots . . B_{I-1} * B_{I}= \\
& \int_{i=1}^{I}\left(R A_{i}+R P_{i}+R A_{i} * R P_{i}\right)+\prod_{i=1}^{I}\left(R A_{i}+R P_{i}+R A_{i} * R P_{i}\right)
\end{aligned}
$$


where $B O S$ is the behavioural outcome space, reflecting the set of decision makers' behaviours, $B_{i}$ is the behavioural outcome of decision maker $I, R A_{i}$ the risk attitude of decision maker $I$, and $R P_{i}$, the risk perception of decision maker $i$.

It is of eminent importance to policy makers to keep the behavioural outcome space as small as possible, as this minimizes the chances of extreme and non-desirable behaviour (Schuster et al., 200I). Minimizing the BOS reduces the uncertainty about citizen reactions, making it easier for policy makers to develop a policy and to communicate it to the people. Moreover, it is easier for policy makers to respond to citizen reactions when their reactions are homogenous.

\section{Risk versus uncertainty in times of crises}

Risk and uncertainty are two different concepts, and the difference is crucial for managing the BOS. A 'risky' situation, as defined previously, is a situation in which the occurrence probability of the risky event is known, as well as the risk content. In real life various situations can be defined as risky. For example, decision makers in the stock market deal with systematic risk, which they can objectively calculate (a stock's Beta). The risk content is well-understood: if you buy a share of stock for US $\$ 20$, the maximum loss you may incur is US\$20. The likelihood of actual exposure to that risk content can be formulated in concrete probabilities.

However, in the types of crises that governments have increasingly been facing, risk is not exactly known or estimable. Will a terrorist attack, for example, manifest itself as the bombing of a building or the hijacking of an airplane? What is the probability of such an attack? In such a situation decision makers are unable to form a risk attitude, as they do not know the exact content of the risk, nor can they form a risk perception, as they are incapable of judging the likelihood (i.e., probability) of exposure to the risk content. In terms of equations (2) and (3), this implies that the risk attitude and risk perception of decision maker $i$ have become uncertain variables themselves in the equation. This results in a flatter distribution function (i.e., larger variances) of risk attitudes and risk perceptions than would have been the case had the risk content and the probability of exposure been known. A flatter distribution in risk attitudes and risk perceptions causes the BOS to increase. That is, since risk attitudes and risk perceptions span the entire behavioural outcome space, this outcome space will increase as risk attitudes and risk perceptions become uncertain variables. This increases the chances of what might be called extreme and, as such, undesirable behaviour within the behavioural outcome space. Extreme or unwanted behaviour may become manifest as individual behaviour, such as a reluctance to travel or stockpiling medication or gasoline, or as collective behaviour, causing economic phenomena such as stock-market crashes, medication shortages, or gasoline shortages and price spikes.

Figure I visualizes the relationships between the BOS on the one hand and the variation of risk attitudes and risk perceptions and their drivers (information density on the content of the risk and on the chance that the risk content occurs, respectively) 
Figure 1 The drivers of the behavioural outcome space

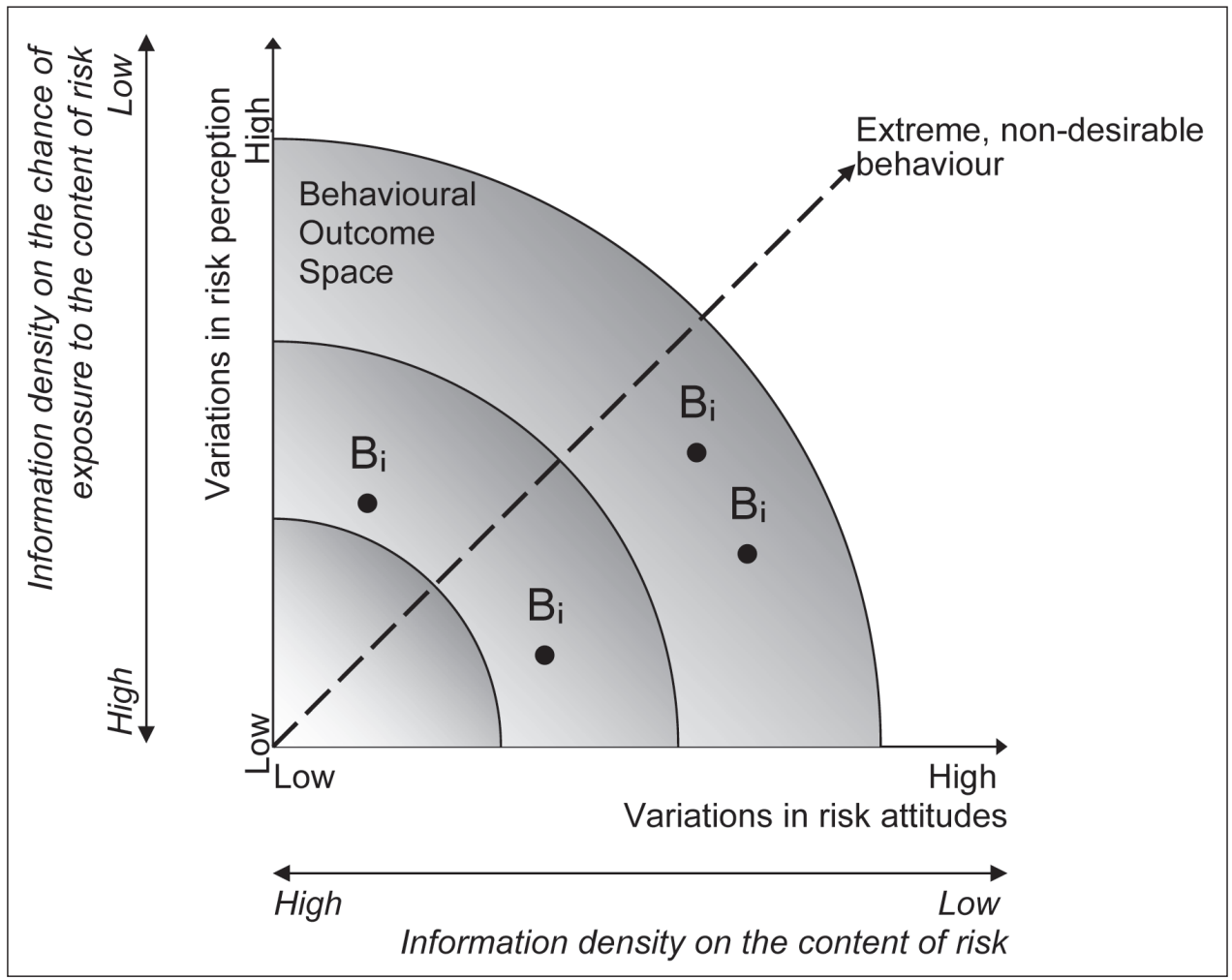

Note: $\mathrm{Bi}$ is the behavioural outcome of decision maker $\mathrm{i}$. The behavioural outcome space is the set of all individual behavioural outcomes. The figure shows that the behavioural outcome space is spanned by the variations in risk attitudes and risk perceptions. These variations increase as the information density on the content of the risk and on the chance of exposure to the risk content decrease, thereby expanding the behavioural outcome space.

on the other hand. Figure I shows that the behavioural outcome space is the sum of the behaviours of all individual decision makers (written in the figure as $\mathrm{B}_{i}$ ).

Policy makers can minimize the BOS by clarifying the risk content (for example, a bomb threat or nuclear threat) and by concretely defining the likelihood of exposure as much as possible (i.e., probabilities or degrees of risk: high, medium or low) (Anand, 2002). It should be noted that the process of influencing the BOS (through the activities of the policy makers, for example) may itself entail risk, which may complicate the efforts of policy makers.

There are natural risks related to shaping outcomes of individual decision making and community behaviour. Risks include such issues as liability, the amount of information available to citizens ('informed consent'), an imbalance in access to information and resources, biases in risk quantification and communication, and government accountability (National Research Council, I989). Another important complication that may present when providing information directly to citizens is that decision making power may be given back to citizens, and citizens may inefficiently or undesirably recreate decision making processes that they originally allocated to government (National Research Council, I989). 
We illustrate and discuss the framework for two crises/disasters-September I I and Hurricane Katrina-because they are different from one another in nature, but similar in I) the media attention, 2) the potential for recurrence within a community and geographic area, and 3) the extrapolation to similar terrorist and natural disaster events worldwide. We wish to illustrate how our framework can provide potential practical help, the ways in which the framework is not able to capture the complexity of a reallife crisis/disaster, and how the framework complements the existing literature.

\section{Government's response to uncertain crises Terrorism warnings}

'More attempts and possible attacks are a distinct possibility. This possibility requires all of us to continue walking the fine line of staying alert on the one hand, without causing undue alarm on the other hand.' Then-Federal Bureau of Investigation Director Robert S. Mueller III (Mueller, 200I).

[Then-Attorney General John Ashcroft said that] the administration chose a conservative course and put out a general warning, although there was not full agreement in the government about whether that was the right thing to do (Rosenbaum and Johnston, 200I).

A heated debate emerged after the Bush administration issued warnings against terrorist attacks. Our framework suggests that this policy is only useful when the government warnings contain information about the content of the risk and the likelihood of exposure to the risk, the two dimensions that help citizens form risk attitudes and risk perceptions, and hence, narrow the BOS (reducing undesirable behaviour). In terms of Figure I: increasing the information density on the content of the risk (i.e., moving from east to west on the $\mathrm{x}$-axis), and increasing the information density on the likelihood of exposure to the risk contest (i.e., moving from north to south on the y-axis) narrows the BOS. Statements that do not contain information about the two dimensions that drive risk attitudes and perceptions will only lead to an expansion of the BOS, thereby increasing the chances of unwanted behaviour. In terms of Figure I, such statements, as quoted above, lead to a shift from west to east on the $\mathrm{x}$-axis and from south to north on the y-axis, thereby expanding the BOS.

On I2 March 2002, Governor Tom Ridge, then-secretary of the US Department of Homeland Security introduced the Homeland Security Advisory System (HSAS). The HSAS is a means of disseminating information regarding the risk of terrorist acts to federal, state and local authorities and to people in the United States. The system's Green, Blue, Yellow, Orange and Red level system (ranging from low to severe) represents the second dimension, as it refers to the general likelihood of exposure to the content of the risk, thereby helping to contribute to the y-axis of the BOS. This system enables decision makers to form more adequate risk perceptions, thereby decreasing the variations in risk perception and narrowing the BOS. The first dimension, the content of a crisis, has not traditionally been clearly formulated in the HSAS, probably for national security reasons. 
The US Government Accounting Office (GAO), in a June 2004 report, acknowledged that to "ensure early and comprehensive information sharing and allow for informed decision making, risk communication experts suggest that threat warnings should include the following principles: (I) communication through multiple methods, (2) timely notification, and (3) specific information on the nature, location, and timing of threats as well as guidance on actions to take in response to threats' (USGAO, 2004, p. 4). Despite these attempts to influence both the risk attitudes and risk perceptions of the threats, the report made clear that federal and state agencies sometimes received notification of threat level changes after it had already been reported by the media, and also that they received little information regarding the site, timing or nature of the threat (USGAO, 2004). As changes are made to the HSAS system, more site-specific threat information is communicated to the public, such as the threat-level increase to Orange on I August 2004 in the financial districts of New York City, Northern New Jersey, and Washington DC. However, little information was made available regarding the timing or nature of the threat (Ganderton et al., 2004). Thus, while citizens' risk perceptions were easily influenced, and the BOS narrowed in that regard, the lack of information about the risk content (thereby reducing the heterogeneity in risk attitudes) could not further narrow the BOS.

As a result, it remains difficult for decision makers to form a risk attitude regarding the imminent threat. Particularly during extremely dangerous crises like terrorism, the BOS is mainly determined by those same risk attitudes (Pennings et al., 2002). Finding ways to meet decision makers' needs for accurate information about the exact contents of crises (i.e., moving from east to west on the x-axis in Figure I) is the main challenge for policy makers. Meeting these needs by, for example, providing real probabilities of risk content to decrease uncertainty, will narrow the BOS and hence contribute to internal stability and unity in times of crisis. Again, the presentation of risk characteristics exist in different formats and with different comparisons, some more appropriate for shaping drivers of citizen decision making than others, and some more appropriate for certain populations than others. The necessity to provide citizens with information that is both high in accuracy, consistency and quality, and from a trusted source is essential (National Research Council, I989). We acknowledge, however, that there may be circumstances in which providing accurate information may conflict with and compromise the mission of government intelligence and defence services.

\section{Hurricane communications}

'We are facing a storm that most of us have long feared . . this is a once-in-a-lifetime event.'

C. Ray Nagin, Mayor of New Orleans (Breed, 2005).

Government communications also affect the actions of citizens in times of natural disaster such as the 2005 US hurricane season, the most costly season of natural disasters ever in the United States. The season included Hurricane Katrina (Gulf Coast/New Orleans, La., 29 August 2005), Hurricane Rita (Texas, 24 September 
2005) and Hurricane Wilma (Florida, 24 October 2005). Questions that were raised by the public after the disaster included: were the citizens properly warned? Why did the evacuation order for Katrina not result in complete evacuation of citizens? What could the government have done to project the risk content of Katrina more adequately? While we are unable to address these questions in detail we discuss them in terms of the proposed conceptual model by examining the information that the citizens received, and how that information affected risk attitudes and risk perceptions. The question then becomes: did the government give appropriate information to create the narrowest BOS possible, leading to outcomes with the greatest societal benefit?

Risk attitude is driven by the risk content: in this context, the degree of destruction and damage that the storm causes. Risk perception in this context is the perceived likelihood that the storm strikes a particular location. One factor that might affect the perceived risk content would be the impact of previous storms, knowledge of which might be gained from memory (if the storm was recent enough), or through information communicated by the government to represent adequately the potential impact of the storm. An assessment of the likelihood of being struck by the storm would be influenced by such services as the National Oceanic and Atmospheric Administration (NOAA), a service of the US Department of Commerce. The NOAA provides stormtracking images that predict the path of the storm, and specifically the probabilities of the eye of the storm striking within a particular geographic area. These images are widely disseminated through the media and via the internet prior to a particularly menacing storm. Thus, information to alter the risk perception of the citizen is easily available and quickly disseminated.

Hurricane Katrina was projected as a Category 5 storm with destructive potential that could mimic Hurricane Camille (New Orleans, I969) and Hurricane Andrew (Florida, I992), and whose impact was foreshadowed by its destructive journey across Cuba before entering the Gulf of Mexico. A hurricane of that magnitude had not struck New Orleans in nearly 45 years. NOAA strike probability maps of Katrina clearly predicted the arrival of the storm to the New Orleans area 48 hours prior to landfall (NOAA, 2005). ${ }^{2}$

In terms of the BOS framework, it seems that the risk content for Katrina was inadequately communicated while the risk probability was adequately communicated through the NOAA projections. Evacuation rates may have been low in certain areas because those citizens did not adequately understand or know the potential power of the storm (risk content thus driving risk attitude), even if they knew the high probability of the storm hitting them (risk perception). Since those citizens did not fully understand the risk content, and therefore were unable to form risk attitudes, they may not have personalized the risk to the potential effects on their lives (Tierney et al., 200I). Despite awareness of disaster increasing with frequent recurrence (Tierney, I993), this may suggest the necessity for improved clarity in the communication of the risk content, including pictures and videos from past hurricane destruction and testimonies from older community members. Since personal experience with a crisis 
increases future accuracy of crisis perception (Tierney, I993) and preparation (Tierney et al., 200I), appealing to older (and theoretically more experienced) community members to aid in communication throughout the community may result in a general improvement of the perception of the content of the crisis' risk. On the other hand, repeat exposure to similar crises may breed a 'disaster subculture', in which community members simply accept the risk and potential loss (Wenger and Weller, I973). This may be especially true for repeated crises with decreased risk content, for example with many years of mild and minimally-damaging storms during the annual hurricane season. In the case of Katrina's strike on New Orleans, the 2004 near-miss of Hurricane Ivan may have encouraged development of the 'disaster subculture' and a numbing effect with respect to hurricane communications (Alexander, 2005). To encourage proper preparation and evacuation with a looming hurricane like Katrina, community members who have seen only minimal damage from hurricanes (and thus are established in the disaster subculture) could be educated by (local) government agencies and by older community members who remember the devastating impact of Hurricane Betsy (1965).

We acknowledge here that myriad other circumstances may result in an incomplete evacuation, including socioeconomic disparities and logistic disorganization. Work by Gladwin and Peacock (I997) has shown that African-American and Hispanic households were less likely to evacuate from Hurricane Andrew, a phenomenon again seen in the African-American community with regard to Hurricane Katrina. This, taken in combination with the difficulty reported by single mothers in responding effectively to hurricane warnings through home preparation and evacuation (Enarson and Morrow, I998), and the influence of poverty, disability, social isolation, and educational level on evacuation (Willigen et al., 2002), created situations where at-risk populations were left largely exposed to the crisis at hand.

\section{Discussion}

The conceptual framework implies that it is beneficial for policy makers to turn an uncertain situation into a risk situation, as it decreases the behavioural outcome space. A practical question for future research is how risk attitudes and risk perceptions are formed, and which means of communication impact upon and shape risk attitudes and risk perceptions. Hence, research on the decision maker's construction of risk perception and risk attitude is needed. Related to that is the question of what are the drivers of risk attitudes and risk perceptions.

The proposed framework is a natural extension of the framework proposed by Kasperson et al. (I988) on the social amplification of risk. Their framework extends the analysis of risk with specific qualities known to influence public responses to crisis, including biases, interests (economic and otherwise) and cultural values.

In any communication event, and importantly in those in times of crises, there is an important balance between the quality and quantity of the information provided. The quality of information provided to citizens must be balanced with the predilection 
to provide ample, even overwhelming, amounts of information. Finally, as addressed by Kasperson et al. (I988), there is the inherent trust that citizens either have or lack in the information from a specific source, and the assumption that response agencies will function according to plan (National Research Council, I996). This is particularly important when considering the various stakeholders who are providing information, and their often diverging goals and disparate methods of achieving those goals (National Research Council, I996).

The proposed framework, for simplicity, does not take into account directly variation based upon factors such as age, race/ethnicity, gender, or socioeconomic status, but indirectly through risk attitude and risk perceptions, as the latter two may be influenced by these factors. It is well known that these factors, among others, play a role in creating different vulnerabilities in the risk population, and thus differences in the response to a crisis or a communication (Phillips and Morrow, 2005). Similarly, the proposed framework cannot account for the citizen's perceived locus of control or belief in the role of a higher power in controlling outcomes related to crisis and disaster (Sims and Baumann, I972). It may, however, contribute to the 'suggestive illustration of how man's personality is active in determining the quality of his interaction with nature' that Sims and Baumann proposed (I972, p. I39I).

The proposed framework assumes a 'command-and-control' model (Tierney, I993), with one central communicator providing information that is aligned around common and agreed-upon goals, with a central route for attaining the goals. In reality, organizations may behave differently during disasters, and may align themselves more along the 'problem-solving' model (Tierney, I993). Further research may examine the nature of a problem-solving model as a driver of the behavioural outcome space.

Trust that an individual citizen has in the source of information is a real-life limitation to today's disaster response and relief efforts, in light of citizen anger toward government responses to Hurricane Katrina. The framework that we propose does not explicitly include trust. In a repeat-play model with inherent contradictory messages, trust becomes increasingly important with each disaster encountered (National Research Council, I989) and by the continued communication of risk by authority figures (Tierney et al., 200I). Further research that integrates trust with the quality and quantity of information in the proposed framework is encouraged.

\section{Conclusion}

Recent crises and disasters have shown that it is difficult for policy makers to respond to citizen reactions to crises. A framework that systematically analyzes how individuals respond to crises, by examining the factors that drive risk behaviour and by relating individual behaviour to aggregate behaviour, may be helpful when developing policies. In this paper we make a first attempt to come up with a framework, rooted in the theory of risk and uncertainty, that analyzes citizens' reactions to crises and disasters in a systematic way. Such a framework may complement previous work 
on both individual and community responses to crises by incorporating the drivers (for example, risk attitude and risk perception) of individual decision making that shape individual and community response toward crises, thereby enriching our knowledge about crises and disaster management. The key element of the framework is that we de-couple risk behaviour in risk attitude and risk perception and that we link these two components to the behavioural outcome space (for example, the set of all individual behavioural outcomes). It is the behavioural outcome space that needs to be managed during a crisis or disaster, which is done through appropriate communication, management, and shaping of risk attitudes and risk perceptions.

\section{Acknowledgements}

We are grateful to the editor and four anonymous referees for their critical comments and suggestions that significantly improved the manuscript. The authors express thanks to the participants of Homeland Security and Ag Bio-Terrorism, $55^{\text {th }}$ Annual Illinois Crop Protection Technology Conference, and to seminar participants at Purdue University, University of Illinois at Urbana-Champaign and Wageningen University in The Netherlands for helpful comments on the research project and preliminary versions of this manuscript.

\section{Correspondence}

Joost M.E. Pennings, Decisions Sciences Group, Department of Marketing, Department of Finance, Maastricht University, Tongersestraat 53, Room BI.I3, 62 I I LM Maastricht, The Netherlands. E-mail: joost.pennings@finance.unimaas.nl.

\section{Endnote}

Joost M.E. Pennings is also Professor in the Marketing \& Decision Sciences Group, Department of Agricultural \& Consumer Economics, University of Illinois at Urbana-Champaign, US, and Professor in the Department of Marketing \& Consumer Behavior, Wageningen University, The Netherlands.

2 NOAA strike probability maps of Hurricane Katrina are provided by the National Hurricane Center and can be seen at http://www.nhc.noaa.gov/archive/2005/KATRINA_graphics.shtml.

\section{References}

Alexander, D. (2005) 'Symbolic and practical interpretations of the Hurricane Katrina disaster in New Orleans'. In the online forum, Understanding Katrina: Perspectives from the Social Sciences. Social Science Research Council, New York. Text at http://understandingkatrina.ssrc.org/Alexander. Anand, P. (2002) 'Decision-making when science is ambiguous'. Science. 295 (556I). p. I839. Arrow, K.J. (I97I) Essays in the Theory of Risk Bearing. Markham Publishing Company, Chicago. 
Barton, A.H. (I969) Communities in Disaster: A Sociological Study of Collective Stress Situations. Doubleday, Garden City.

Breed, A.G. (2005) Immense Hurricane Roars Toward New Orleans. Associated Press. 28 August. Text at http://www.ohsep.louisiana.gov/archive/katrinaroars.htm.

Chen, K., G. Hitt, L. McGinley and A. Petersen (200I) 'Trial and error: seven days in October spotlight weakness of bioterror response-Health officials were slow to grasp anthrax hazard for D.C. postal workers-Mad dash from Brentwood'. The Wall Street Journal. 2 November.

Drabek, T.E. and J.E. Haas (I969) 'Laboratory simulation of organizational stress'. American Sociological Review. 34. pp. 223-38.

Dynes, R.R. (I970) Organized Behavior in Disaster. D.C. Heath, Lexington.

Enarson, E. and B.H. Morrow (eds.) (1998) The Gendered Terrain of Disaster: Through Women's Eyes. International Hurricane Research Center, Florida International University, Miami.

Fritz, C.E. (I96I) 'Disasters'. In R.K. Merton and R.A. Nisbet (eds.) Contemporary Social Problems. Harcourt, New York.

Fritz, C.E. and E.S. Marks (I954) 'The NORC studies of human behavior in disaster'. Journal of Social Issues. IO. pp. 26-4I.

Ganderton, P.T., D.S. Brookshire and R.L. Bernkopf (2004) 'Improving the Homeland Security Advisory System: an experimental analysis of threat communication for national security'. Unpublished report. Text at http://gandini.unm.edu/research/Papers/HSASGanderton.pdf.

Gladwin, H. and W.G. Peacock (I997) 'Warning and evacuation: a night for hard houses'. In W.G. Peacock, B.H. Morrow and H. Gladwin (eds.) Hurricane Andrew: Ethnicity, Gender and the Sociology of Disasters. International Hurricane Research Center, Florida International University, Miami.

Heath, T.B., S. Chatterjee and K.R. France (I995) 'Mental accounting and changes in price: the frame dependence of reference dependence'. Journal of Consumer Research. 22 (I). pp. 90-97.

Hirshleifer, J., and J.G. Riley (I992) The Analytics of Uncertainty and Information. Cambridge University Press, Cambridge.

Kasperson, R.E., O. Renn, P. Slovic, H.S. Brown, J. Emel, R. Goble, J.X. Kasperson and S. Ratick (I988) 'The social amplification of risk: a conceptual framework'. Risk Analysis. 8 (2). pp. I77-87. Knight, F.H. (I933) Uncertainty and Profit. Houghton Mifflin, Boston.

MacCrimmon, K.R. and D.A. Wehrung (1986) Taking Risks: The Management of Uncertainties. Free Press, New York.

Menon, G., L.G. Block and S. Ramanathan (2002) 'We're at as much risk as we are led to believe: effects of message cues on judgements of health risk'. Journal of Consumer Research. 28. pp. 533-49.

Mileti, D.S., C. Fitzpatrick and B.C. Farhar (I990) Risk Communication and Public Response to the Parkfield Earthquake Prediction Experiment: Final Report to the National Science Foundation. Hazards Assessment Laboratory, Colorado State University, Fort Collins.

Mileti, D.S. and C. Fitzpatrick (I992) 'The causal sequence of risk communication in the Parkfield earthquake prediction experiment'. Risk Analysis. I2. pp. 393-400.

Mueller, R.S. (200I) 'Remarks'. Given at the Mayors' Emergency, Safety, and Security Summit, United States Conference of Mayors, Washington DC. 24 October. Text at http://canberra.usembassy. gov/hyper/200I/IO24/epf306.htm.

National Research Council (I989) Improving Risk Communication. National Academy Press, Washington DC.

National Research Council (I996) Understanding Risk: Informing Decisions in a Democratic Society. National Academy Press Washington DC.

NOAA (National Oceanic \& Atmospheric Administration) (2005) 'Hurricane Katrina strike probabilities'. US Department of Commerce, NOAA, National Weather Service, Silver Spring. 28 November. Text at http://www.nhc.noaa.gov/archive/2005/KATRINA_graphics.shtml. 
Pennings, J.M.E. and A. Smidts (2000) 'Assessing the construct validity of risk attitude'. Management Science. 46 (IO). pp. I337-48.

Pennings, J.M.E. and A. Smidts (2003) 'The shape of utility functions and organizational behavior'. Management Science. 49 (9). pp. I25I-63.

Pennings, J.M.E. and B. Wansink (2004) 'Channel contract behavior: the role of risk attitudes, risk perceptions, and channel members' market structures'. Journal of Business. 77. pp. 697-723.

Pennings, J.M.E., B. Wansink and M.T.G. Meulenberg (2002) 'A note on modeling consumer reactions to a crisis: the case of the mad cow disease'. International Journal of Research in Marketing. I9 (I). pp. 9I-IO0.

Pennings, J.M.E., P. Garcia and E. Hendrix (2005) 'Towards a theory of revealed economic behavior: the economic-neurosciences interface'. Journal of Bioeconomics. 7 (2). pp. II3-27.

Phillips, B.D. and B.H. Morrow (2005) 'Social science research needs: a focus on vulnerable populations, forecasting and warnings'. Paper presented at the Hurricane Forecast Socio-economic Workshop, Pomona. I6-I8 February. Text at http://www.sip.ucar.edu/pdf/ozVulnerable_Populations_ Forecasting_and_Warnings.pdf.

Pratt, J.W. (1964) 'Risk aversion in the small and in the large'. Econometrica. 32 (January-April). pp. I $22-36$.

Quarantelli, E.L. (1990) The Warning Process and Evacuation Behavior: The Research Evidence. Preliminary Paper No. I48. Disaster Research Center, University of Delaware, Newark. Text at http:// dspace.udel.edu:8080/dspace/handle/19716/520.

Quarantelli, E.L. (I997) 'Ten criteria for evaluating the management of community disasters'. Disasters. 2I (I). pp. 39-56.

Rosenbaum, D.E. and D. Johnston (200I) 'A nation challenged: the alert; Ashcroft warns of terror attacks soon against US'. The New York Times. 30 October.

Schuster, M.A., B. D. Stein, L. Jaycox, R.L. Collins, G.N. Marshall, M.N. Elliott, A.J. Zhou, D.E. Kanouse, J.L. Morrison and S.H. Berry (200I) 'A national survey of stress reactions after the September II, 200I terrorist attacks'. N Engl J Med. 345 (20). pp. I507-I2.

Sims, J.H. and D.D. Baumann (1972) 'The tornado threat: coping styles of the North and South'. Science. I76 (4042). pp. I386-92.

Slovic, P. (1987) 'Perceptions of risk'. Science. 236 (4799). pp. 280-85.

Tierney, K.J. (1993) Disaster Preparedness and Response: Research Findings and Guidance from the Social Science Literature. Preliminary Paper No. 193. Disaster Research Center, University of Delaware, Newark. Text at http://dspace.udel.edu:8080/dspace/handle/I97I6/579.

Tierney, K.J., M.K. Lindell and R.W. Perry (200I) Facing the Unexpected: Disaster Preparedness and Response in the United States. Joseph Henry Press, Washington DC.

Tversky, A. and D. Kahneman (198I) 'The framing of decisions and the psychology of choice'. Science. 2II. pp. $453-58$.

USGAO (US Government Accounting Office) (2004) Homeland Security: Communication Protocols and Risk Communication Principles Can Assist in Refining the Advisory System. GAO-04-682. June. Text at http://www.gao.gov/new.items/do4682.pdf.

Viscusi, W.K. (I997) 'Alarmist decisions with divergent risk information'. Economic Journal. I07. pp. I657-70.

Wenger, D.E. and J.M. Weller (1973) Disaster Subcultures: The Cultural Residues of Community Disasters. Preliminary Paper No. 9. Disaster Research Center, University of Delaware, Newark. Text at http:// dspace.udel.edu:8080/dspace/handle/I97I6/399.

Willigen, M.V., T. Edwards, B. Edwards and S. Hessee (2002) 'Riding out the storm: experiences of the physically disabled during Hurricanes Bonnie, Dennis and Floyd'. Natural Hazards Review. 3 (3). pp. 98-106. 